\title{
RINOSCLEROMA. DESCRIPCIÓN DE UN CASO
}

\section{Rhinoscleroma. A case report}

Luis Enrique SÁNCHEZ-SIERRA; Carlos Felipe MATUTE-MARTíNEZ; Daniel Martín BARAHONA-LÓPEZ; Miguel BANDES; Ana Raquel URBINA; Flor GIRÓN

Universidad Nacional Autónoma de Honduras. Facultad de Ciencias Médicas. Tegucigalpa. Honduras.

Correspondencia: daniel200706@hotmail.com

Fecha de recepción: 28 de enero de 2017

Fecha de aceptación: 16 de febrero de 2017

Fecha de publicación: 18 de febrero de 2017

Fecha de publicación del fascículo: 1 de diciembre de 2017

Conflicto de intereses: Los autores declaran no tener conflictos de intereses

Imágenes: Los autores declaran haber obtenido las imágenes con el permiso de los pacientes

Política de derechos y autoarchivo: se permite el autoarchivo de la versión post-print (SHERPA/RoMEO) Licencia CC BY-NC-ND. Licencia Creative Commons Atribución-NoComercial-SinDerivar 4.0 Internacional Universidad de

Salamanca. Su comercialización está sujeta al permiso del editor

RESUMEN

Introducción: El rinoscleroma es una patología crónica rara descrita en 1870 por Von Hebra ocasionada por Klebsiella pneumoniae subespecie rhinoscleromatis. Descripción: Paciente varón de 24 años con tumor en ambas fosas nasales de cuatro años de evolución. Discusión: El rinoscleroma es una enfermedad lentamente progresiva que se presenta en tres etapas: atrófica, granulomatosa y fibrótica. Conclusiones: El diagnóstico adecuado permite un manejo clínico y tratamiento médico oportuno.

PALABRAS CLAVE escleroma respiratorio; rinoscleroma; klebsiella rhinoscleromatis; enfermedad granulomatosa

SUMMARY Introduction: Rhinoscleroma is a rare chronic disease described in 1870 by Von Hebra caused by Klebsiella pneumoniae subspecies rhinoscleromatis. Description: A 24-year-old male patient with a tumor in both nostrils of four years of evolution. Discussion: Rhinoscleroma is a slowly progressive disease that occurs in three stages: atrophic, granulomatous and fibrotic. Conclusions: Adequate diagnosis allows clinical management and timely medical treatment.

KEYWORDS

respiratory scleroma; rhinoscleroma; klebsiella rhinoscleromatis; granulomatous disease

\section{INTRODUCCIÓN}

El rinoscleroma es una enfermedad rara, crónica, lentamente progresiva, granulomatosa e infecciosa del tracto respiratorio superior [1]. El término rinoscleroma fue acuñado por primera vez en 1870 por Von Hebra, quien describió una lesión nasal clasificándola como un tipo de sarcoma [2]. En 1877 Mikulicz describió en detalle las características histológicas del rinoscleroma, estableciendo su etiología inflamatoria y no neoplásica 
[3]. Hasta el año 1882 Von Frish logró identificar el agente causal de la patología, la bacteria Klebsiella rhinoscleromatis, subespecie de Klebsiella pneumoniae, un diplobacilo Gram negativo encapsulado no móvil, perteneciente al subgrupo KES (Klebsiella, Enterobacter y Serratia) o enterobacteriaceae [1, 4]. El rinoscleroma es una enfermedad endémica en zonas tropicales y subtropicales, Europa del este, noreste africano, América Central, Sudamérica, Indonesia y países de Oriente Medio, además se presenta de forma esporádica en el resto del mundo fundamentalmente en zonas rurales y áreas de baja condición socioeconómica $[1,5]$. La incidencia y prevalencia de la enfermedad es escasa sin embargo más de 16.000 casos se han registrado en diferentes partes del mundo desde 1960 [6].

Las características clínicas del rinoscleroma son más manifiestas durante la fase granulomatosa, los cambios histológicos más sobresalientes en esta fase se caracterizan por infiltración de linfocitos, células plasmáticas, cuerpos de Russell y células de Mikulicz [5]. El cultivo bacteriano de las muestras de biopsia sigue siendo el método más útil para el diagnóstico de rinoscleroma (positivo en $50 \%$ de los pacientes en la etapa granulomatosa) [7], aunque también por medio de técnicas de inmunohistoquímica se puede detectar el antígeno Klebsiela tipo III [8].

Se presenta un caso de rinoscleroma en fosa nasal derecha y obstrucción parcial de la misma, con el objetivo de mostrar la importancia de identificar esta entidad en su etapa temprana e inicio oportuno del tratamiento para evitar compromiso de otras estructuras.

\section{DESCRIPCIÓN}

Paciente varón de 24 años de edad, campesino, procedente de Choluteca (Honduras) que presentaba historia de masa en fosa nasal derecha de 4 años de evolución, de crecimiento progresivo, acompañada de epistaxis espontánea y episodios de obstrucción nasal. El paciente afirmaba tener hábitos no saludables como tabaquismo, consumo de alcohol y marihuana, sin antecedentes personales ni familiares de la enfermedad.

Al examen físico se hallaron signos vitales dentro de parámetros normales, oídos con pabellones auriculares simétricos, conductos auditivos externos permeables y membranas timpánicas integras. Nariz con dorso asimétrico, desviación septal lateral hacia lado derecho, aumento de tamaño en dorso nasal derecho, masa en fosa nasal derecha de aspecto carnoso con restos hemáticos, sin rinorrea ni epistaxis activa en la rinoscopia anterior (Figura 1). La boca con buena apertura, sin lesiones en la mucosa; en cuello se encontraron adenopatías en cadena cervical posterior profunda derecha. El resto del examen físico estuvo dentro de parámetros normales.

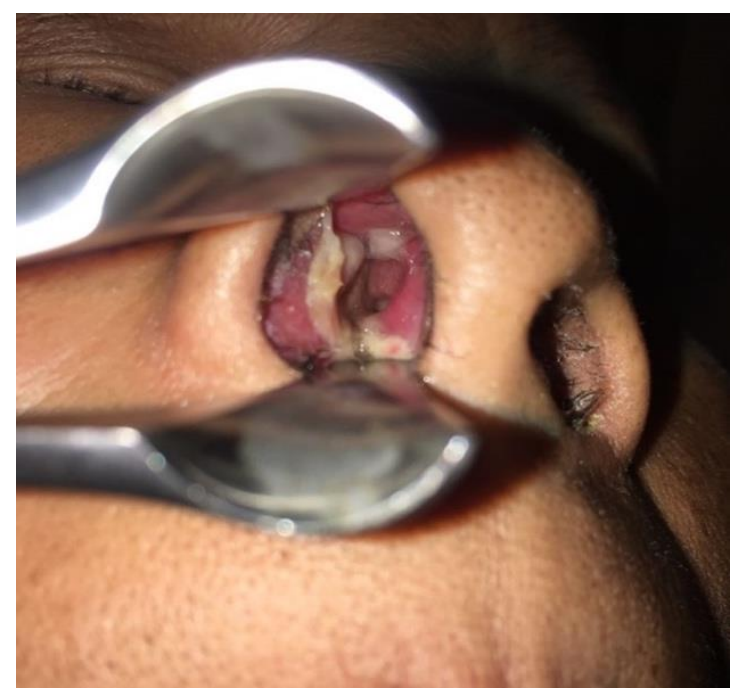

Figura 1. Masa en fosa nasal derecha de aspecto carnoso con restos hemáticos, sin rinorrea, ni epistaxis activa en la rinoscopia anterior.

Se realizaron estudios de imagen con tomografía axial computarizada con cortes axiales y coronales con espesor de $4 \mathrm{~mm}$, analizando las imágenes con ventana ósea y tejidos blandos. Se informó de masa en ambas fosas nasales de predominio derecho con obstrucción y desviación del tabique nasal, ocupando completamente la fosa nasal derecha y la región de las celdillas etmoidales inferiores, respetando las estructuras óseas del tabique y la pared medial de los senos maxilares, opacidad maxilar, de las celdillas etmoidales derechas y del seno esfenoidal derecho, el seno maxilar izquierdo se encontró limpio. El diagnóstico radiológico fue de tumoración en fosa nasal derecha con efecto de masa que produce desplazamiento del tabique nasal y opacidad del seno maxilar derecho, esfenoidal y etmoidales ipsilaterales. Se realizó biopsia de la lesión, las muestras fueron enviadas al departamento de patología. En los cortes examinados se identificaron nódulos revestidos de epitelio respiratorio, las regiones centrales presentaban tejido conectivo con abundantes células de Mikulicz e inflamación crónica y aguda inespecífica. 
Los cortes histológicos mostraron agregados de macrófagos espumosos (células de Mikulicz) mezcladas con linfocitos y células plasmáticas con epitelio escamoso sin atipia (Figura 2). No se evidenciaron microorganismos con la tinción de Gram y ácido peryódico de Schiff (PAS). Las tinciones de inmunohistoquímica CD68 y vimentina fueron positivas en los macrófagos (Figura 2); CD10, CK AE1/AE3 y S100 fueron negativos. Posteriormente se envió para estudio inmunohistoquímico (Tabla 1) que reportó lesión compuesta por agregados de histiocitos sin atipia con citoplasma claro y en área granular eosinofílica, entremezclados con abundantes linfocitos y células plasmáticas, se identificaron ocasionales vasos con infiltrado neutrofílico en su pared.

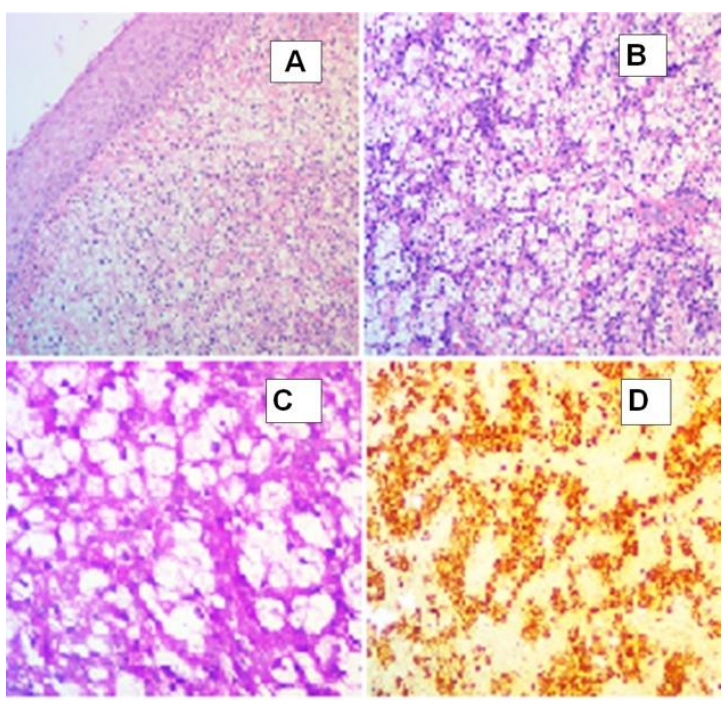

Figura 2. Agregados de histiocitos espumosos (células de Mikulicz). A- Tejido parcialmente cubierto por epitelio escamoso sin atipia, bajo el que se identifican numerosos histiocitos (HE 4x). B- A mayor aumento se observa el infiltrado inflamatorio con predominio de histiocitos y linfocitos (HR 10x). C- Tinción de PAS, que muestra histiocitos espumosos, sin identificarse microorganismos (PAS 40x). D. Tinción de inmunohistoquímica para CD68 que muestra positividad marcada en los histiocitos espumosos.

La muestra enviada para cultivo microbiológico no reportó crecimiento bacteriano, en base a los hallazgos de laboratorio, histopatológicos y de inmunohistoquímica se estableció el diagnóstico de rinoscleroma nasal.

Se pautó tratamiento antibiótico con ciprofloxacino a dosis de 500 mg vía oral cada 12 horas que continuó hasta 17 días y diclofenaco a dosis de $75 \mathrm{mg}$ vía oral cada 12 horas y lavados nasales con 1 litro de agua, $20 \mathrm{ml}$ de peróxido de hidrógeno (agua oxigenada) y $15 \mathrm{ml}$ de bicarbonato de sodio al $7,5 \%$, en ambas fosas nasales. El tratamiento definitivo fue cirugía endoscópica naso-sinusal (CENS) resecando completamente el tejido patológico encontrado.

Tabla 1. Características inmunohistoquímicas

\begin{tabular}{|l|c|}
\hline \multicolumn{1}{|c|}{ Marcadores } & $\begin{array}{c}\text { Resultado } \\
\text { CD68 }\end{array}$ \\
\hline CD10 & $\begin{array}{c}\text { Positivo membranoso en los his- } \\
\text { tiocitos }\end{array}$ \\
\hline CKAE1/ AE3 & Negativo \\
\hline Melan A & Negativo \\
\hline Vimentina & Negativo \\
\hline Actina & Positivo en los histiocitos \\
\hline
\end{tabular}

\section{DISCUSIÓN}

El rinoscleroma es una enfermedad lentamente progresiva con inicio insidioso y curso indolente. Presenta mayor incidencia en el sexo femenino (relación 13:1), afecta predominantemente la cavidad nasal (95 a 100\% de los casos), pudiendo afectar también la nasofaringe (18\% a 43\%), laringe (15\% a $40 \%)$, tráquea $(12 \%)$ y bronquios (2\% a $7 \%$ ). Otras áreas que pueden verse involucradas son la cavidad oral, senos paranasales, y tejidos blandos de los labios y la nariz. En raros casos se extiende a la órbita [5, 9, 10]. En este caso la presentación del rinoscleroma fue con predominio en fosa nasal derecha y sin afectación de otras estructuras.

La enfermedad se clasifica clinicopatológicamente en tres etapas:

1. Una etapa inicial o catarral (atrófica), la que se caracteriza por la presencia de sintomatología similar al resfriado común, con obstrucción de una o ambas fosas nasales. En esta etapa es posible observar hipertrofia de la membrana mucosa.

2. Una segunda etapa proliferativa donde disminuyen los síntomas de resfriado. Aquí predomina la reacción granulomatosa, la cual puede progresar en forma variable hasta afectar faringe y laringe pudiendo ocasionar dificultad respiratoria.

3. La etapa final (esclerótica) consiste en el depósito de colágeno, llevando así a la fibrosis con distorsión anatómica de las estructuras afectadas durante los estadios anteriores $[6,9,11]$.

Este paciente se presentó en fase proliferativa o granulomatosa, con carencia de síntomas de 
resfriado, sin afectación de estructuras adyacentes de la vía aérea, se intervino quirúrgicamente por medio de CENS y días después presentó estenosis secundaria en fosa nasal derecha la cual fue corregida posteriormente.

El agente K. pneumoniae subespecie rhinoscleromatis no se encuentra normalmente en secreciones nasales por lo que su obtención en medio de cultivo de McConkey es diagnóstica de la enfermedad. A pesar de lo anterior esto solo es posible en un $50-60 \%$ de los casos [12]. Las características clínicas del rinoscleroma nasal son más floridos durante la fase granulomatosa, de igual forma los cambios histológicos para el diagnóstico son más prominentes en esta fase, la cual se caracteriza por infiltración de linfocitos, células plasmáticas, cuerpos de Russell y células de Mikulicz —estas son un criterio histopatológico patognomónico del rinoscleroma- En un estudio retrospectivo realizado en Egipto se concluyó que el predominio de células plasmáticas y ausencia de eosinófilos en biopsias de pacientes con síntomas nasales crónicos debe plantear la posibilidad de rinoscleroma independientemente de la detección de células de Mikulicz en particular en zonas endémicas [5].

Se deberá realizar el diagnóstico diferencial en estadios tempranos con rinosinusitis bacteriana crónica y rinitis atrófica, y, en estadios tardíos, con tuberculosis, actinomicosis, lepra, paracoccidioidomicosis, síflis secundaria, leishmaniasis cutánea, rinosporidiosis, sarcoidosis, granulomatosis de Wegener, granuloma facial, linfomas, sarcomas, carcinoma epidermoide y pólipos nasales [9, 13]. En este caso, al estudio histopatológico realizado en los cortes de tejido examinados, se identificaron nódulos revestidos de epitelio respiratorio, las regiones centrales presentaron tejido conectivo con abundantes células de Mikulicz e inflamación crónica y aguda inespecífica y marcadores de inmunohistoquímica propios de la enfermedad con positividad para CD68.

El tratamiento farmacológico de elección para el tratamiento microbiano empírico son las fluoroquinolonas como el ciprofloxacino por un periodo de seis meses, debido a su excelente actividad contra bacilos Gram negativos, eficacia intracelular, baja toxicidad, excelente penetración al tejido, concentración dentro de los macrófagos y buena tolerancia [11, 13, 14]. Como segunda opción se emplean tetraciclinas por igual periodo o hasta obtener un resultado de cultivo negativo en biopsia nasal, se ha observado que el empleo de ciprofloxacino junto con rifampicina ha permitido alcanzar concentraciones altas en macrófagos y secreciones nasales $[12,15,16]$. Si la presencia de tejido fibroso ocasiona obstrucción grave o deformación de las fosas nasales, se recomienda la extirpación quirúrgica del tejido a través de la cirugía endoscópica [13,16]. En el caso descrito, el tratamiento antibiótico facilitó una evolución satisfactoria y se realizó cirugía para resecar completamente la masa de tejido fibroso secundaria a rinoscleroma que ocupaba completamente la fosa nasal derecha y región de las celdillas etmoidales inferiores.

\section{CONCLUSIONES}

El rinoscleroma es una entidad poco frecuente pero es necesario tenerla presente cuando un paciente proveniente de una zona endémica de la enfermedad se presenta con una lesión en fosas nasales, sin causa traumática evidente. Un diagnóstico adecuado permite un manejo clínico y tratamiento médico oportuno, los cuales mejoran el pronóstico.

\section{BIBLIOGRAFÍA}

1. Ortega JR, Velasco FJ, Santamaría SF. Rinoscleroma. Una entidad a considerar en la rutina diaria del patólogo. Rev Esp Patol. 2016;49(1):32-6.

2. Von Hebra F. Uber ein eigenthumliches neugebilde an der nase: rhinosklerom: nebst histologischem befunde von Dr M Kohn. Wien Med Wochenschr. 1870;20:1-5.

3. Mikulicz J. Uber das Rhinosklerom (Hebra). Langenbechs Arch Klin Chir. 1877;20:485-534.

4. Von Frisch A. Zur Aetiologie des Rhinoscleroms. Wien Med Wochenschr. 1882;32:969-82.

5. Ahmed ARH, El-badawy ZH, Mohamed IR, Abdelhameed WA. Rhinoscleroma: a detailed histopathological diagnostic insight. Int J Clin Exp Pathol. 2015;8(7):8438-45.

6. Hart CA, Rao SK. Rhinoscleroma. J Med Microbiol. 2000;49(5):395-6.

7. Gumprecht TF, Nichols PW, Meyer PR. Identification of rhinoscleroma by immunoperoxidase technique. Laryngoscope. 1983;93(5) 627-9.

8. Meyer PR, Shum TK, Becker TS, Taylor CR. Scleroma (Rhinoscleroma). A histologic immunohistochemical study with bacteriologic correlates. Arch Pathol Lab Med. 1983;107 (7):377-83. 
9. Alcalá Pérez D, Arias AC, Navarrete G. Rinoescleroma. Comunicación de un caso. Dermatología Rev Méx. 2009;53(3):156-9.

10. Ollague JM, Avilez IT. Rinoescleroma: Caso Clínico. Rev Ecuator Dermatol [en línea]. 2003 [citado 12 Feb 2017]; 1 (1): [1 páginas]. Disponible en: http://www.medicosecuador.com/revistadermat ologia/vol1num1/rinoescleroma.html.

11. De Pontual L, Ovetchkine $P$, Rodríguez $D$, Grant A, Puel A, Bustamante J, et al. Rhinoscleroma: a French national retrospective study of epidemiological and clinical features. Clin Infect Dis. 2008;47(11):1396-402.

12. Segura-Vílchez J, González-Rojas P, RetanaMoreira L. Rinoescleroma. Acta Méd Costarric. 2013;55(1):53-5.
13. Navazo Eguía Al, García Vicario F. Rinoescleroma. Acta Otorrinolaringol Esp. 2010;61(2):160-2.

14. Bhowate RR, Degwekar S, Rawlani S, Dangore $\mathrm{S}$. Rhinoscleroma with involvement of the maxillary sinus, orbital floor, and temporomandibular joint: a case report. J Oral Maxillofac Surg.2012;70 (1):135-40.

15. Méndez Gonzaga O, López Chavira A. Ciprofloxacina en el tratamiento de la rinoescleroma respiratoria. Rev Sanid Milit Mex. 2001;556):256-60.

16. Del Villar U M, Vallejos U MP, Arregui R, Vega C C, Medina G D. Rinoescleroma, una enfermedad rara en Chile: Reporte de un caso clínico. Rev Otorrinolargol Cir Cabeza Cuello. 2004;64:127-33. 